\title{
Development of Immunosensor Platform based on Reversibly Assembled IgG Micropaterns for Detection of Non-healing Wound Biomarkers ${ }^{\dagger}$
}

\author{
Edita Voitechovič ${ }^{*}$, Tomas Rakickas ${ }^{1}$ and Ramūnas Valiokas ${ }^{1}$ \\ 1 Center for Physical Sciences and Technology (FTMC); Department of Nanoengineering; Savanoriu ave. 231 \\ LT-02300 Vilnius; Lithuania \\ * Correspondence: edita.voitechovic@ftmc.lt \\ + Presented at the 7th Electronic Conference on Sensors and Applications, 15 - 30 November 2020; Available \\ online: https://ecsa-7.sciforum.net/.
}

Published: 15 November 2020

\begin{abstract}
The diagnosis of non-healing wounds is a challenge nowadays, because there is no single biomarker, and, usually, each case of the non-healing wound is individual. All this together impedes the development of point-of-care diagnostic systems for the wound. In current research we suggest four possible wound healing and unhealing biomarkers-proteins, which could be used as targets for the monitoring of the wound exudate during wound healing progress. Based on this choice, we designed prove-of-the-concept studies, in which the first stage is a development of analytical platform based on imaging SPR for selected biomarkers.
\end{abstract}

Keywords: wound; biomarker; trisNTA; immunosensor; SPR; microcontact printing; exudate; antibody; micropattern

\section{Introduction}

The number of people who are suffering because of non-healing wounds and chronic ulcers is growing rapidly. Overall ca. $2 \%$ of all population have non-healing wounds during their lifetime that significantly affects morbidity of the people and results in costs on the level of billions of euros for the therapy [1]. Such situation is getting worse because there is no cost effective and robust method for the analysis of the wound and/or its fluids (wound exudate), which can determine the type of the wound (healing or not) and predict a process of the wound healing. Many scientists are working worldwide under the development of the point-of-care analytical devices for the wound assessment. Recently, the methods as near infrared spectroscopy [2], electrochemical [3], bioelectrochemical [4], even electronic nose [5] were suggested for the monitoring and the diagnosis of the non-healing wounds. Unfortunately, none of that methods is available nowadays as the accurate and reliable technique for the application in the hospitals for the patient treatment. The reasons for that are numerous, one of them is insufficient accuracy, especially in the cases, when the wound is monitored by only one parameter.

The healing process of the wound is complex and consisted of four main stages: hemostasis, inflammation, proliferation and remodeling. The difference between healing and non-healing wounds is that the non-healing wound is all the time at the inflammation stage and the next stage proliferation doesn't begin. Recent proteomic studies demonstrated the changes in the composition of the proteins, which are in the wound exudate, depending on the wound healing stage [6]. We performed a thorough literature review of existing biomarkers of the wound, and we have selected four possible targets for the analysis, which were not used yet all together for the 
assessment of the wound healing stage: matrix metalloproteinase-9 (MMP-9); transforming growth factor $\beta 1$ (TGF- $\beta 1$ ); interleukin-10 (IL-10); and fibronectin (FN).

Possibly, the only way for the development of analytical device for these four biomarkers is a construction of the affinity biosensor. The biosensor have to meet some highly important criteria in order to be suitable for everyday use in hospitals or at home for personal monitoring. The main challenge for the analysis of wound exudate is to detect as low as several picograms of the biomarker in the limited amount of the wound exudate (usually around $50 \mu \mathrm{l}$, but different authors declare the range of 20-2500 $\mu \mathrm{l}$ [7]), which can contain up to $50 \mathrm{mg} / \mathrm{ml}$ of other proteins, without additional preparations or sophisticated treatment of the real sample before the analysis.

The goal of current research was a development of a biosensor-on-chip analytical platform (BioCAP) with the reversibly assembled antibody micropaterns. The main feature of the proposed BioCAP is a simple regeneration of the surface and reversibility in the immobilization of the antibodies. It provides the possibility to obtain same amount of the active antibodies on the BioCAP surface each time after the regeneration for precise analysis of the biomarkers. To reach such task we used multivalent chelator - trisnitrilotriacetic acid (trisNTA) for high-affinity reversible binding of oligohistidine (His)-tagged protein A (SpA) from Staphylococcus aureus and consequent immobilization of immunoglobulin $\mathrm{G}(\mathrm{IgG})$. SpA is well known protein in immunosensor development since it binds IgG through its Fc domain and orients the antibody on the surface with the Fab domain, which captures biomarkers, to the top [8]. Such IgG orientation on the surface allows obtaining the maximum amount of the active antibodies for the detection of the biomarkers. An imaging surface plasmon resonance (iSPR) was selected as the method for the registration of the BioCAP modifications and biomarker bindings because of its accuracy, possibility to monitor proteinsurface and protein-protein interactions in real time without addition of the labels [9].

\section{Materials and Methods}

\subsection{Materials}

Tri(ethylene glycol)terminated alkylthiols with -OH and -OMe functional groups: $\mathrm{HS}-\left(\mathrm{CH}_{2}\right)_{11-}$ EG3-OH $(\mathrm{EG} 3-\mathrm{OH})$ and $\mathrm{HS}-\left(\mathrm{CH}_{2}\right)_{11}-\mathrm{EG} 3-\mathrm{OMe}(\mathrm{OMe})$, consequently, were obtained from Prochimia (Poland). Thiol containing tri(ethylene glycol) unit and trisNTA functional group HS- $\left(\mathrm{CH}_{2}\right)_{11}-\mathrm{EG}_{3}-$ trisNTA (Fig. 1) was synthesized in the FTMC (Lithuania) following the protocol described elsewhere [10]. Recombinant Protein A (SpA) with His6-Tag and rabbit polyclonal antibody type IgG to MMP-9 were obtained from Abcam (UK). Other materials used for the research were at the analytical grade of purity and were obtained from the Merk group companies (Europe). Ultrapure water (resistivity 18.2 $\mathrm{M} \Omega \cdot \mathrm{cm}$ at $25^{\circ} \mathrm{C}$ ) was taken directly from a Synergy 185 unit equipped with a UV lamp (Millipore, USA). Nitrogen gas class $5.0\left(\mathrm{~N}_{2}\right)$ was used for drying samples and sample handling tools.

\subsection{Formation of Protein-repellent Patterns and Functional Zones}

The BioCAP was made on the gold coated (44 nm) SF10 glass slides (Au-SF10) (Accurion, Germany) forming the self-assembled monolayers (SAMs) of protein-repellent patterns from OMe and protein-binding zones from the mixture of trisNTA and EG3-OH. Before the modifications, the Au-SF10 slide was cleaned by the procedure, described earlier in [10]. Immediately after Au-SF10 cleaning, microcontact printing $(\mu \mathrm{CP})$ with OMe [11] was performed for formation of the proteinrepellent micro-sized grid. For the formation of these patterns, a polydimethylsiloxane (PDMS) stamp, made by Baltfab (Lithuania) with grid structures (with $20 \mu \mathrm{m}$ width protruding grid and $75 \times 75 \mu \mathrm{m}^{2}$ recessed squares), was inked with a solution of the OMe in ethanol, kept for $1 \mathrm{~min}$ and dried in a flow of $\mathrm{N}_{2}$. Afterwards, the stamp was brought in contact with the Au surface and then rinsed with the ethanol (99,9\%). The optimization of the OMe concentration and the stamp exposure time on the gold surface for $\mu \mathrm{CP}$ was performed with the gold substrate AuSsens (20 nm Au on silicon, Ssens, the Netherlands). In order to form the SAM between the grid structures, the Au-SF10 slide was incubated in the mixture of trisNTA and EG3-OH (sum concentration was $20 \mu \mathrm{M}$ ) in ethanol overnight at room temperature in the dark. The fraction of trisNTA in this mixture varied aiming to 
found optimum trisNTA surface density. After deposition of functional zones, modified Au-SF10 slide was rinsed twice in ethanol $(99,9 \%)$ and dried in a flow of $\mathrm{N}_{2}$.

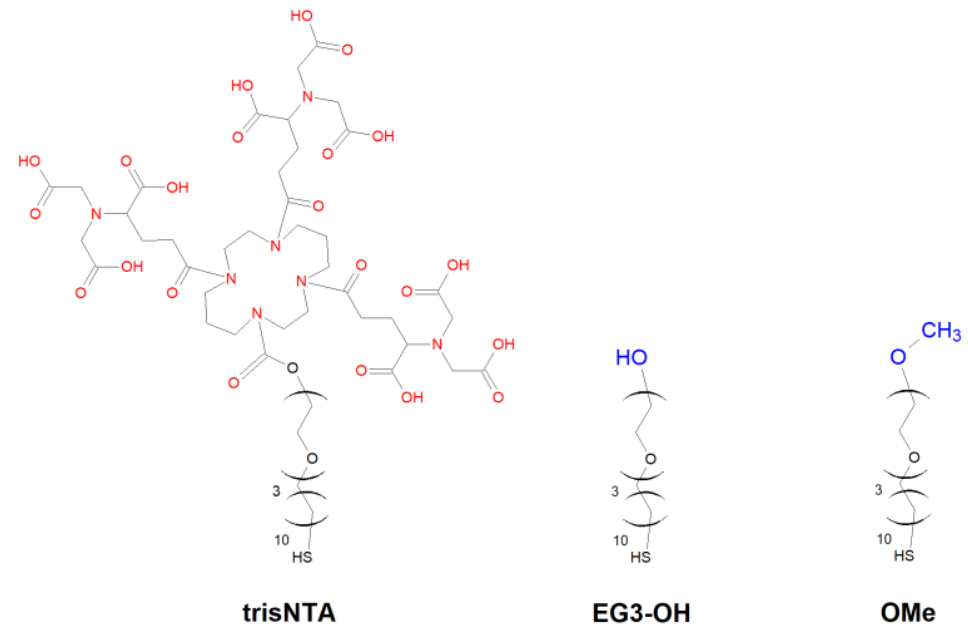

Figure 1. Structures of the alkanethiols with different functional groups for SAM formation.

\subsection{Ellipsometric Measurements}

The modification of the surface of Au-SF10 slide and AuSsens substrate was monitored by single-wavelength imaging null-ellipsometer Nanofilm EP3, equipped with a laser emitting at the $658 \mathrm{~nm}$ wavelength (Accurion, Germany). The thickness of the SAM was evaluated in the air measuring the sample reflectance characteristics change at the angle of incidence of $60^{\circ}$. The thickness of the SAM was modelled applying the Accurion data analysis program, EP4 Model. The SAM-AuSF10 sample was modelled as a four layer system consisting of Glass-SF10, $\mathrm{Cr}$, Au and 'organic' (SAM) layers, respectively. The SAM-AuSsens sample was modelled as a five layer system consisting of crystalline silicon, silicon dioxide, $\mathrm{Ti}, \mathrm{Au}$ and 'organic' (SAM) layers, respectively. The refractive index values for Glass-SF10, Cr, Crystalline silicon, silicon dioxide, Ti and Au were taken from the inbuilt databases. The SAM was modelled as an 'organic' layer with a refractive index of $n=1.5$ and $\mathrm{k}=0$.

\subsection{Kinetic Measurements}

ISPR measurements were performed with SAM-Au-SF10 slide with Nanofilm EP3 in a SPR cell, according to the Kretschmann configuration. The flow cell was $\sim 100 \mu \mathrm{L}$. Measurements were carried out at fixed angle of incidence that was $0.1^{\circ}$ below SPR resonance angle (usually ca. $56.6^{\circ}$ ). The ellipsometric parameters $\Delta$ and $\Psi$, averaged over selected regions of interest, were recorded over time at $20 \mathrm{~s}$ intervals. With this set of parameters, $\Delta$ was inversely proportional to mass density increase on the slide surface. The changes in the surface thickness due to protein-surface and proteinprotein interactions were modeled by EP4 Model applying five layers system consisting of glass$\mathrm{SF} 10, \mathrm{Cr}, \mathrm{Au}$, 'organic' (surface and proteins) layers and buffer. The assumption, that 'organic' layer thickness of $1 \mathrm{~nm}$ corresponds to the cover of $100 \mathrm{ng} / \mathrm{cm}^{2}$ of organic molecules, was applied for the data interpretation. The kinetic measurements were performed in a HBS+T buffer: $20 \mathrm{mM}$ of HEPES, $150 \mathrm{mM} \mathrm{NaCl}, 0.001 \%$ Tween 20, $\mathrm{pH} 7.5$ at room temperature. All protein solutions used in the research were made in the same HBS+T buffer, except the $100 \mathrm{mM}$ of $\mathrm{HCl}$ aqueous solution. A continuous flow system was used at $50 \mu \mathrm{L} / \mathrm{min}$ for the buffer, $\mathrm{HCl}$, imizadole, $\mathrm{NiCl}_{2}$, EDTA, and at $10 \mu \mathrm{L} / \mathrm{min}$ for the all protein solutions.

\section{Results and Discussion}

\subsection{Protein-repellent Patterns}


First of all , the SAM of OMe was formed by dipping the AuSsens substrate into freshly prepared ethanolic solution containing $40 \mu \mathrm{M}$ of OMe for $24 \mathrm{~h}$, as such conditions can form SAM with good stability and bioinertness [12]. Obtained SAM ellipsometric thickness was $1.82 \pm 0.13 \mathrm{~nm}$, therefore the optimal thickness after $\mu \mathrm{CP}$ with OMe have to reach similar value. We applied simple factorial design for variation of two factors: OMe concentration and stamp exposure time on the gold substrate surface. It was defined, that the stamp exposure time on the gold surface influenced the ellipsometric thickness of the pattern layer in higher extent comparing to the OMe concentration. We have defined that $0.75 \mathrm{mM}$ of $\mathrm{OMe}$ and $10 \mathrm{~min}$ of stamp exposure time were the optimum conditions for $\mu \mathrm{CP}$, which resulted in formation of the grid patterns of 1.8-2.05 nm. Such $\mu \mathrm{CP}$ conditions were applied for the formation of the grid pattern on the Au-SF10 slides as well. The obtained protein-repellent grid was tested in the kinetic measurements with different proteins. It was found that formed OMe grid did not bind the tested proteins (SpA, BSA), however little amount (as low as $0.05 \mathrm{~nm}$ ) of IgG can be unspecifically attached on the OMe patterns after antibody loading (Fig. 2 A). Such low amount of IgG did not influence the sensitivity and the accuracy of the further kinetic measurements.

\subsection{Functional Zones of the BioCAP and Their Properies}

SAMs, consisted of fractions of EG3-OH and trisNTA, have already demonstrated favorable packing and orientation of the trisNTA functional group at the ambient/SAM interface for effective multivalent adsorption of the proteins with polyhistidine tag [10]. It was also shown that the low surface density trisNTA SAMs provided a more selective capturing of proteins and detection of binding partners. Therefore in current research we perform the experiments for the optimization of the concentration of the trisNTA for the mixed SAM formation, which would satisfy the conditions for the selective biomarker determination: (1) the trisNTA surface density should bind such amount of SpA, which later ensures sufficient IgG surface density; (2) all surface molecules of trisNTA should participate in the specific SpA binding, aiming to avoid unspecific adsorption of the other proteins; (3) the whole specifically adsorbed SpA should be captured by the selected IgG, otherwise there is a risk, that other antibodies from the real sample can attach to SpA as well and defect the biomarker determination.

The trisNTA fraction in the solution for SAM formation, the concentrations of SpA and IgG were varied applying the factorial design. The total concentration of the functional alkanethiols for SAM formation was $20 \mu \mathrm{M}$, while the fraction of trisNTA was varied in the range of $5-20 \% \mathrm{~mol}$. The ellipsometric thickness of the obtained functional zones in the air was 1.95-2.2 nm and wasn't influenced by the trisNTA fraction concentration, similarly, as it was obtained in [10].

The first kinetic measurements of the functional SAM, formed from the solution with $5 \% \mathrm{~mol}$ of trisNTA, resulted in extremely low SpA specific adsorption (an increase of ellipsometric thickness of the SpA layer was ca. $0.02 \mathrm{~nm}$, comparable to the unspecific binding to OMe). Therefore the following SAMs were formed with the trisNTA fractions of 10 and $20 \% \mathrm{~mol}$. The functional zones formed from $20 \%$ mol trisNTA solution were able to compose the SpA layer of 1.8-1.83 nm (180-183 $\left.\mathrm{ng} / \mathrm{cm}^{2}\right)$. However, such high amount of the SpA on the surface impeded IgG binding, possibly, due to the steric hindrance. In contrary, functional zones formed from the trisNTA of $10 \%$ mol, attached significantly lower amount of SpA (as low as $0.1 \mathrm{~nm}$ or $10 \mathrm{ng} / \mathrm{cm}^{2}$ ), though consequent binding of IgG produced only ca. $0.2 \mathrm{~nm}$ layer $\left(20 \mathrm{ng} / \mathrm{cm}^{2}\right)$. Such IgG surface density was also not good enough for BioCAP, because well oriented and well packed IgG on the surface for effective bioanalysis is in the range of $81-150 \mathrm{ng} / \mathrm{cm}^{2}$ [13]. Therefore, some intermediate values of SpA surface density can satisfy the amount of the well packed IgG. Factorial design of the variation of three parameters, as described above, resulted in the observations that the highest influence on the IgG surface density possessed trisNTA fraction concentration and IgG solution concentration, which was used for the immobilization of the IgG. The best results, which were obtained at current stage of the research were: SpA layer of $24 \mathrm{ng} / \mathrm{cm}^{2}$, which adsorbed $200 \mathrm{ng} / \mathrm{cm}^{2}$ of IgG. However, these results were obtained with the BioCAP, where the functional zones were made from the $20 \%$ mol fraction of trisNTA. Therefore only ca. $10 \%$ of the whole surface trisNTA participated in the specific binding, that can finally result in the unspecific protein attachments. Also, the mixed adsorption of the IgG: specific to 
$\mathrm{SpA}$ and unspecific to trisNTA-Ni ${ }^{2+}$ cannot be excluded. Further experiment will involve study of the BioCAP with intermediate trisNTA fraction concentrations. Also, the evaluation of the trisNTA surface density will be performed by other methods, such as XPS and IR spectroscopy, because it seems, that the trisNTA fraction concentration in the SAM solution does not directly correlate to the factual trisNTA concentration on the surface in the functional zones.

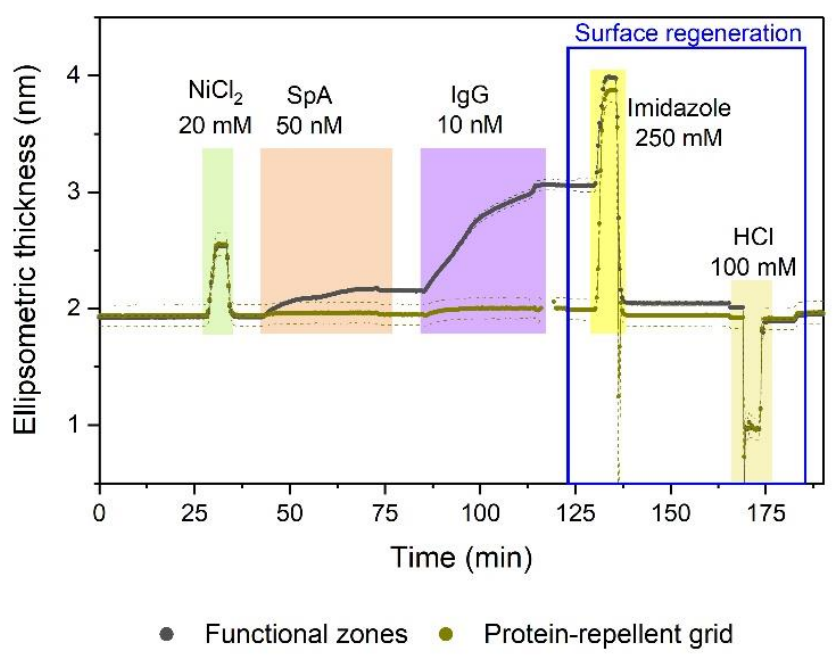

(a)

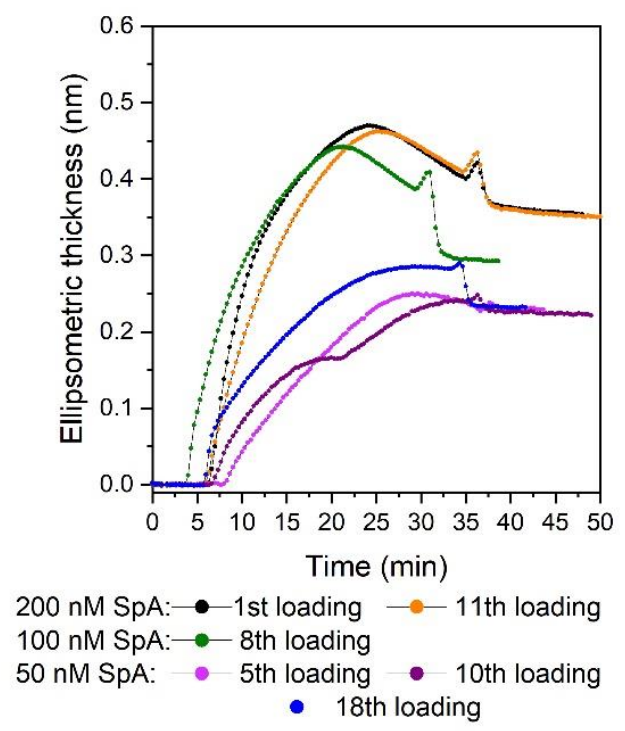

(b)

Figure 2. (A) General workflow of the kinetic measurements with BioCAP. The HBS+T was used as a running buffer. Elution of the protein complex was done with imidazole or dissociation with $\mathrm{HCl}$. (B) Iterations of the SpA loadings.

The regeneration of the functional zones was performed with the elution by imidazole. As it was defined in the previous studies [10], $250 \mathrm{mM}$ of imidazole is optimal concentration for the effective regeneration of the trisNTA. However, in some cases, a low amount of the SpA-IgG complex (up to $0.1 \mathrm{~nm}$ ) can remain on the surface, but short surface exposure to $0.1 \mathrm{M}$ of $\mathrm{HCl}$ removes it (Fig. $2 \mathrm{~A}$ ). At current stage of the research up to 20 re-immobilization cycles of proteins were performed without losing of the sensitivity of the functional zones (Fig. 2 B).

The further development of the flow cell design, aiming to minimize the cell volume to ca. $10 \mu \mathrm{l}$ and to install multichannel module, will allow us to obtain much faster mixing of the protein solutions in the cell, that consequently will result in the possibility to evaluate the kinetic parameters of the protein bindings, and to analyze synchronously at least two biomarkers.

\section{Conclusions}

Current research was devoted to an initial stage of the development of multisensing platform on the basis of reversible assembled IgG type antibodies, which are selective to the wound biomarkers. The platform was made on the gold slides, modified by the protein-repellent coating and functional zones with reversible binding of IgG by SpA. The protein-repellent coating was formed by $\mu \mathrm{CP}$ with OMe, obtaining SAM layer. The conditions for $\mu \mathrm{CP}$ was optimized, and the grid patterns of 1.8-2.05 nm were made on the gold-glass slide. Functional zones were formed with the mixed SAM of EG3-OH and multivalent chelator - trisNTA, reaching 1.95-2.2 nm thickness, where trisNTA trough $\mathrm{Ni}^{2+}$ interacts with $\mathrm{SpA}$ with six oligohistidines (His6-Tag). It was defined, that overloading of the SpA on the surface impeded binding of the IgG. Therefore the trisNTA concentration on the surface is a critical parameter for the optimal SpA surface concentration, which, consequently, result in the stable and reproducible IgG immobilization. 
Author Contributions: Conceptualization and methodology, E.V., T.R. and R.V.; investigation, analysis, writing-original draft preparation, visualization, funding acquisition E.V.; curation, resources, writingreview and editing, T.R. and R.V. All authors have read and agreed to the published version of the manuscript.

Funding: This research was funded by the European Social Fund under agreement with the Research council of Lithuania (LMTLT), grant number 09-3.3-LMT-K-712-08-0004.

Conflicts of Interest: The authors declare no conflict of interest.

\section{References}

1. Sami, D. G.; Heiba, H. H.; Abdellatif, A., Wound healing models: A systematic review of animal and nonanimal models. Wound Med. 2019, 24, 8-17, doi:10.1016/j.wndm.2018.12.001.

2. Sowa, M. G.; Kuo, W. C.; Ko, A. C. T.; Armstrong, D. G., Review of near-infrared methods for wound assessment. J. Biomed. Opt. 2016, 21, doi:10.1117/1.JBO.21.9.091304.

3. Ashley, B. K.; Brown, M. S.; Park, Y.; Kuan, S.; Koh, A., Skin-inspired, open mesh electrochemical sensors for lactate and oxygen monitoring. Biosens. Bioelectron. 2019, 132, 343-351, doi:10.1016/j.bios.2019.02.041.

4. Roychoudhury, S.; Umasankar, Y.; Jaller, J.; Herskovitz, I.; Mervis, J.; Darwin, E.; Hirt, P. A.; Borda, L. J.; Lev-Tov, H. A.; Kirsner, R.; Bhansali, S., Continuous monitoring of wound healing using a wearable enzymatic uric acid biosensor. J. Electrochem. Soc. 2018, 165, B3168-B3175, doi:10.1149/2.0231808jes.

5. Haalboom, M.; Gerritsen, J. W.; van der Palen, J., Differentiation between infected and non-infected wounds using an electronic nose. Clin. Microbiol. Infect. 2019, 25, 1288.e1-1288.e6, doi:10.1016/j.cmi.2019.03.018.

6. Cavassan, N. R. V.; Camargo, C. C.; de Pontes, L. G.; Barraviera, B.; Ferreira, R. S.; Miot, H. A.; Abbade, L. P. F.; dos Santos, L. D., Correlation between chronic venous ulcer exudate proteins and clinical profile: A cross-sectional study. J. Proteomics 2019, 192, 280-290, doi:10.1016/j.jprot.2018.09.009.

7. Trengove, N. J.; Langton, S. R.; Stacey, M. C., Biochemical analysis of wound fluid from nonhealing and healing chronic leg ulcers. Wound Repair Regen. 1996, 4, 234-239, doi:10.1046/j.1524-475X.1996.40211.x.

8. Ultsch, M.; Braisted, A.; Maun, H. R.; Eigenbrot, C., 3-2-1: Structural insights from stepwise shrinkage of a three-helix Fc-binding domain to a single helix. Protein Eng. Des. Sel. 2017, 30, 619-625, doi:10.1093/protein/gzx029.

9. Templier, V.; Livache, T.; Boisset, S.; Maurin, M.; Slimani, S.; Mathey, R.; Roupioz, Y., Biochips for direct detection and identification of bacteria in blood culture-like conditions. Sci. Rep. 2017, 7, doi:10.1038/s41598017-10072-z.

10. Valiokas, R.; Klenkar, G.; Tinazli, A.; Reichel, A.; Tampé, R.; Piehler, J.; Liedberg, B., Self-assembled monolayers containing terminal mono-, bis-, and tris-nitrilotriacetic acid groups: Characterization and application. Langmuir 2008, 24, 4959-4967, doi:10.1021/la703709a.

11. Morhard, F.; Pipper, J.; Dahint, R.; Grunze, M., Immobilization of antibodies in micropatterns for cell detection by optical diffraction. Sens. Actuators B Chem. 2000, 70, 232-242, doi:10.1016/s0925-4005(00)005748.

12. Hayashi, T.; Tanaka, Y.; Koide, Y.; Tanaka, M.; Hara, M., Mechanism underlying bioinertness of selfassembled monolayers of oligo(ethyleneglycol)-terminated alkanethiols on gold: protein adsorption, platelet adhesion, and surface forces. Phys. Chem. Chem. Phys. 2012, 14, 10196-10206, doi:10.1039/C2CP41236E.

13. Zhao, X.; Pan, F.; Cowsill, B.; Lu, J. R.; Garcia-Gancedo, L.; Flewitt, A. J.; Ashley, G. M.; Luo, J., Interfacial immobilization of monoclonal antibody and detection of human prostate-specific antigen. Langmuir 2011, 27, 7654-7662, doi:10.1021/la201245q.

Publisher's Note: MDPI stays neutral with regard to jurisdictional claims in published maps and institutional (C) 2020 by the authors. Submitted for possible open access publication under the terms and conditions of the Creative Commons Attribution (CC BY) license (http://creativecommons.org/licenses/by/4.0/).

affiliations. 